\title{
Samsum ant venom modulates the immune response and redox status at the acute toxic dose in vivo
}

\author{
Hossam Ebaid ${ }^{1 *} \mathbb{D}$, Bahaa Abdel-Salam², Ibrahim Alhazza1, Jameel Al-Tamimi', Iftekhar Hassan', Ahmed Rady, \\ Ashraf Mashaly ${ }^{1}$, Ahmed Mahmoud ${ }^{1}$, Reda Sammour ${ }^{1}$ \\ ${ }^{1}$ Department of Zoology, College of Science, King Saud University, Riyadh 11451, Saudi Arabia. \\ ${ }^{2}$ Department of Biology, College of Science and Humanities in El-Quwiaya, 11961, Shaqra University, Saudi Arabia.
}

\section{Keywords:}

Samsum ant venom

Polymorphonuclear cells (PMNs)

Costimulatory molecules (CD80 and CD86)

Major histocompatibility complex (MHC)

MHC-II

Interferon gamma (INF- $\gamma)$

Interleukin-17 (IL-17)

\begin{abstract}
Background: Ant venoms express surface molecules that participate in antigen presentation involving pro- and anti-inflammatory cytokines. This work aims to investigate the expression of MHC-II, CD80 and CD86 on the polymorphonuclear cells (PMNs) in rats injected with samsum ant venom (SAV).

Methods: Rats were divided into three groups - control, SAV-treated (intraperitoneal route, $600 \mu \mathrm{g} / \mathrm{kg}$ ), and SAV-treated (subcutaneous route, $600 \mu \mathrm{g} / \mathrm{kg}$ ). After five doses, animals were euthanized and samples collected for analysis.

Results: The subcutaneous SAV-trated rats presented decreased levels of glutathione with increased cholesterol and triglyceride levels. Intraperitoneal SAV-treated animals displayed significantly reduced concentrations of both IFN- $\gamma$ and IL-17 in comparison with the control group. However, intraperitoneal and subcutaneous SAV-treated rats were able to upregulate the expressions of MHC-II, CD80 and CD86 on PMNs in comparison with the control respectively. The histological examination showed severe lymphocyte depletion in the splenic white pulp of the intraperitoneal SAV-injected rats. Conclusion: Stimulation of PMNs by SAV leads to upregulation of MHC-II, CD 80, and CD 86, which plays critical roles in antigen presentation and consequently proliferation of T-cells. Subcutaneous route was more efficient than intraperitoneal by elevating MHC-II, CD80 and CD86 expression, disturbing oxidative stability and increasing lipogram concentration.
\end{abstract}

* Correspondence: hossamebaid1969@gmail.com http://dx.doi.org/10.1590/1678-9199-JVATITD-2019-0020 Received: 16 May 2019; Accepted: 5 November 2019; Published online: 2 December 2019 


\section{Background}

Polymorphonuclear cells (PMNs) possess a short half-life in the circulatory system because they constitutively undergo apoptosis [1]. Under certain conditions, PMNs play a vital role in the effector arm of host immune defense through clearance of immune complexes, phagocytosis of opsonized particles, and release of inflammatory mediators [2]. Traditionally, considered to be the first line of defense against bacterial infection, it is clear that PMNs also participate in chronic inflammation and regulation of the immune response when appropriately activated [3]. PMN infiltration plays a pivotal role in inflammation that is also attributive of tissue damage during the inflammatory response [4]. During infection, the host immune system activates the inflammatory response by attracting the neutrophils to the site of infection. The immune cells engulf the cell debris and release ROS to heighten immune response. It further attracts pro-inflammatory macrophages (M1) that engulf the neutrophils as well as trigger enhanced production of ROS that leads to a transition from M1 to M2 (anti-inflammatory macrophages). M2 finally release many anti-inflammatory cytokines including IL-10 and tissue growth factors to promote tissue repair [5, 6]. Besides, through interactions with various cells of the immune system, such as antigen-presenting cells and lymphocytes, neutrophils, M2 also influence inflammatory responses [7, 8].

The samsum ant Brachyponera sennaarensis (Formicidae: Ponerinae) is primarily found in many parts of Saudi Arabia. The sting of this ant generally results in pain, inflammation, and irritation in humans. However, sometimes, it can lead to severe allergic reactions ranging from mild ones to anaphylactic shock $[9,10]$. Despite its documented adverse effects, the toxin at precise doses shows promising pharmacological properties [11]. In addition, we have previously hypothesized that samsum ant venom (SAV) can induce acute toxic inflammation via activation of PMNs as part of their mechanism of toxic effects in vivo.

Moreover, PMNs can express MHC-II and co-stimulatory molecules (CD80 and CD86) surface molecules [12, 13]. Under certain stimulatory states, PMNs can present MHC-II-restricted antigens [14] or can acquire MHC-II antigens in the course of the disease [15]. It is likely that the change of MHC-II into PMN may serve as a novel diagnostic marker for active immune responses. Therefore, the present study was conducted to evaluate the expression of MHC-II and co-stimulatory CD80 and CD86 on PMNs in response to host exposure to the SAV to ascertain if these cells are indeed activated during SAV induced host inflammatory response. In addition, the study also investigated if SAV is more efficient by subcutaneous (SC) route or intraperitoneal (IP) injection.

\section{Methods}

\section{Collection of samsum ants and dissection of the venom glands}

Samsum ant colonies were collected from Hotat Bani Tamim Governorate, Kingdom of Saudi Arabia. The ants were placed in plastic containers $(20 \times 70 \mathrm{~cm})$ with upper interior edges painted with grease to prevent their exit. A glass tube was inserted into each case to provide a $10 \%$ sugar solution twice a day. At the time of venom harvest, ants were dissected and their sting apparatus was dettached by grabbing the last segment of the abdomen and detaching it with the sting apparatus under microscopic magnification. Venom glands were pooled, homogenized and the resulting mash was then centrifuged at $1000 \mathrm{rpm}$ for two minutes at $4^{\circ} \mathrm{C}$ [16]. The resulting supernatant was collected and lyophilized into powder. SAV dry powder was diluted in phosphate buffered saline (PBS, $\mathrm{pH} 7.4$ ) at the concentration of 2 $\mathrm{mg}$ of venom in $1000 \mu \mathrm{L}$ PBS. The venom solution was stored at $-25^{\circ} \mathrm{C}$ until use. On average, $0.5-2 \mu \mathrm{L}$ of venom can be extracted from an ant gland depending on the size, food availability, breed of the ant, and expertise to collect the venom. In the present study, 35 ants were subjected to the extraction of the venom.

\section{Experimental design and ethics approval}

Wister rats (males, 220-270 g, $\approx 20$ weeks old) were obtained from Departmental Animal House (Zoology Department, King Saud University, Riyadh). They were housed in pathogen-free facilities maintained at $22 \pm 2{ }^{\circ} \mathrm{C}$ with $45-65 \%$ of relative humidity and $14 / 10$-hour light/dark cycle. It is reported that the dose of SAV at $600 \mu \mathrm{g} / \mathrm{kg}$ affected physiologically and histopathologically treated rats [17]. Besides, the subcutaneous dose of the venom has been applied in several studies to induce colonic precancerous and cancerous model in rats [18]. The venom has been extensively studied to check its wound healing properties in open wounds on rat skin [19]. In the present investigation, the rats were assigned into three groups $(\mathrm{n}=10)$ - control (injected with $1 \mathrm{~mL}$ of saline only), intraperitoneal (IP) injection of SAV, and subcutaneous (SC) injection of SAV. The five doses of SAV $(600 \mu \mathrm{g} / \mathrm{kg}$ in $1 \mathrm{~mL}$ to each rat) were administered on every third day in both IP and SC groups. After 24 hours of the last injection, all rats were sacrificed and the samples collected for analysis. All the experiments conducted on animals were approved by the Departmental Animal Ethical Committee (College of Science, King Saud University, Riyadh) under approval number 3/2/110623.

\section{Toxicity test of SAV in vivo}

The acute toxicity of the crude SAV was assessed by using Wister rats. Sixty rats, after adapting for three days, were randomly divided into 12 groups $(n=5)$. The pure extract of SAV was dissolved in deionized water. All rats were allowed free access to fresh water and food after administration. Bliss assay was used to calculate $\mathrm{LD}_{50}$ by recording cumulative mortality within 14 days [20].

\section{Assay of biochemical parameters}

Serum biochemistry

The blood from the retro-orbital venous sinus of each rat was collected into two tubes, one with EDTA for FACS analysis, and the second for serum. Blood samples were centrifuged at 3000 $\mathrm{rpm}$ for 10 minutes at $4^{\circ} \mathrm{C}$. The sera were separated and stored 
at $-25^{\circ} \mathrm{C}$. The serum concentrations of both cholesterol and triglyceride were evaluated using kits (Quimica Clinica Aplicada S.A., Spain) for spectrophotometry (Pharmacia Biotech, UK).

Estimation of lipid peroxidation (MDA) and reduced glutathione (GSH)

About half of the spleen from rats of each group was used for the assessment of lipid peroxidation (MDA) and glutathione (GSH). For this, the splenic tissues were homogenized (Automated homogenizer, IKA, T25D, Germany) in $10 \mathrm{mM} \mathrm{KCl}$ in $1.15 \%$ PBS and ethylenediaminetetraacetic acid (EDTA; $\mathrm{pH} 7.4$ ) and centrifuged at $5000 \times \mathrm{g}$ for 10 minutes. The resulting supernatant was used to estimate the level of MDA and GSH by the established methods $[21,22,23]$.

\section{Measurement of immune factors}

The concentrations of major immune factors including IFN- $\gamma$ and IL-17 were estimated in the sera by ELISA according to the manufacturer's instructions for the corresponding rat immunoassay kits (Abcam, UK). The optical densities of the ELISA plate were measured at $450 \mathrm{~nm}$. The level of sensitivity of the kits was $100 \mathrm{pg} / \mathrm{mL}$.

\section{Fluorescence-activated cell sorter (FACS) analysis}

For FACS of blood, the samples were collected in the non-EDTA coated tubes that were mixed $100 \mu \mathrm{L}: 2 \mathrm{~mL}$ with FACS lysing solution (Becton Dichinson, Germany). Dyes like fluorescein isothiocyanate (FITC)-anti-CD80 and phycoerythrin (PE)labeled-anti-CD86, and MHC-DP+DQ+DR:PE monoclonal antibodies (Coulter Immunotech, France) were obtained to label the cells for analyses. After staining of the cells with antibodies (in dark at room temperature for $30 \mathrm{~min}$ ), they were washed followed by their study in a FACS Calibur system using CellQuest software (Becton Dickinson, USA). A minimum of three events/sample was acquired. All results were expressed as the percentage of marker-positive cells in a respective gate.

\section{Histological studies}

At necropsy, the liver and spleen of each rat were removed, weighed, and placed in neutral buffer in $10 \%$ formalin for 24 hours. The tissues were then processed in paraffin wax and were cut into 4 - $\mu \mathrm{m}$ sections. After that sections were stained with haematoxylin and eosin (H\&E) to highlight microscopic details of general histological architecture.

\section{Statistical analysis}

The results were expressed as mean $(\mathrm{M}) \pm$ standard deviation (SD). The one-way ANOVA statistical was analyzed by using MINITAB software (State College, PA, Version 13.1, 2002).

\section{Results}

Two injection routes were employed in this study, the subcutaneous (SC) and the intraperitoneal (IP) injection of
SAV. Results are summarized in Table 1.

\section{The effect of SAV on the lipidogram}

The rats treated with subcutaneous injection of SAV showed significant increase in the concentrations of both total cholesterol and triglycerides by $7.6 \%$ and $260 \%$, respectively, compared to the control goroup (Figure 1). In contrast, the intraperitoneal injection of SAV did not alter levels of these two parameters concerning the control to that extent.

\section{The effect on the lipid peroxidation and glutathione}

The level of MDA and GSH was not significantly changed in rats treated via IP route as compared to the control group (Figure 2). However, rats that had received SAV via the SC route evidenced a decrease in total glutathione concentration by $~ 50 \%$ when compared to controls (Figure 2).

\section{Estimation of IFN- $\boldsymbol{\gamma}$ and IL-17}

IP injection of SAV resulted in a significant decrease in IFN- $\gamma$ and IL-17 levels by $40.01 \%$ and $35.7 \%$, respectively, when compared with the control group (Figure 3). In comparison, no significant change was observed in the level of both cytokines in rats injected via SC route.

\section{PMNs, MHC-II, CD80, and CD86 expression}

FACS analysis of the samples showed that MHC-II expression on PMNs of control rats was $2.9 \%$ (Figure $4 \mathrm{~A}$ ). This value was significantly lower than that of rats that had received the SC SAV injection (7.2\%, Figure 4B) or the intraperitoneal (IP) injection (10.7\%, Figure 4C).

Analyses of CD80 expression on host PMNs showed that control rat cells had a level of 3.0\% (Figure 5A). Again, this value was significantly lower than that observed in cells from rats that had received the SC SAV injection (20.3\%, Figure 5B) or the IP injection (9.5\%, Figure 5C). These same patterns were also evident with regard to analysis of PMN CD86 expression, i.e., while control rat PMN had 3.0\% expression levels (Figure $6 \mathrm{~A})$, there were significant differences between controls (3.00\%), subcutaneous-injected (13.07\%) and intraperitoneally-injected (7.01\%) hosts (Figure 6).

\section{Histopathological alterations \\ Spleen}

Histologic examination of the spleens indicated there were effects on the white and red pulp of rats that received SAV via IP route (Figure 7). Depletion of lymphocytes and infiltration of megakaryocytes were also noted in these rats. The histological examination of the splenic tissues in Figure 7 revealed severe and intense alterations in SC SAV-treated animals. A depletion of the white pulp lymphocytes was remarkably noted compared to the healthy tissues. Infiltration with megakaryocytes and different other cells was clearly observed in tissue of SC SAVtreated animals. 
Table 1. Different categories of test parameters for intraperitoneal and subcutaneous routes of SAV injection in male rats.

\begin{tabular}{|c|c|c|}
\hline Categories of test parameter & IP route & SC route \\
\hline Triglycerides (TAGs) & $\mathrm{n}$ & + \\
\hline Cholesterol & $\mathrm{n}$ & + \\
\hline Lipid peroxidation (MDA) & $\mathrm{n}$ & $\mathrm{n}$ \\
\hline Reduced glutathione (GSH) & $\mathrm{n}$ & - \\
\hline Interferon gamma (IFN- $\gamma)$ & - & $\mathrm{n}$ \\
\hline Interleukin-17 (IL-17) & - & $\mathrm{n}$ \\
\hline MHC-II expression & +++ & ++ \\
\hline CD 80 expression & ++ & ++++ \\
\hline CD 86 expression & ++ & ++++ \\
\hline Spleen damage & ++ & +++ \\
\hline Liver damage & ++ & ++++ \\
\hline
\end{tabular}

n: no significant changes; +: increase; ++: twofold increase; +++: three-fold increase: ++++: four-fold increase; -: decrease; IP:intraperitoneal route; SC: subcutaneous route. All the fold-increase and decrease were compared with the control under histological analysis.

\section{Triglyceride}

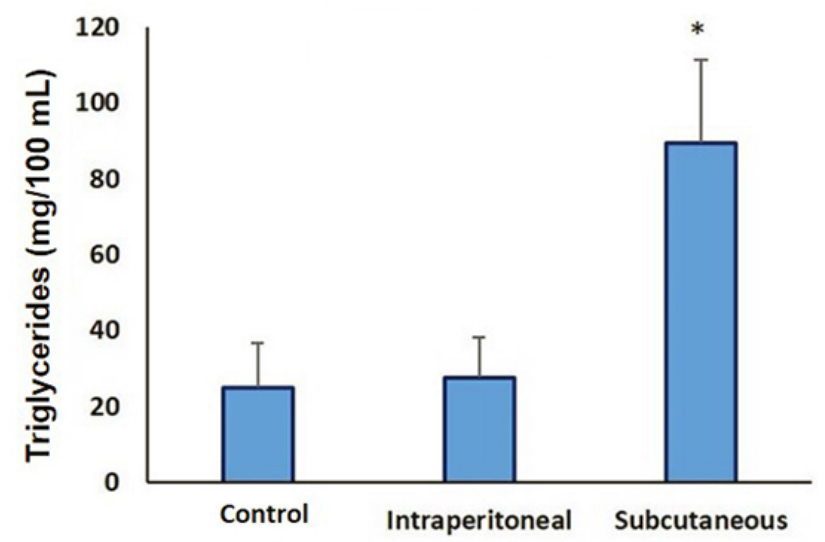

cholesterol

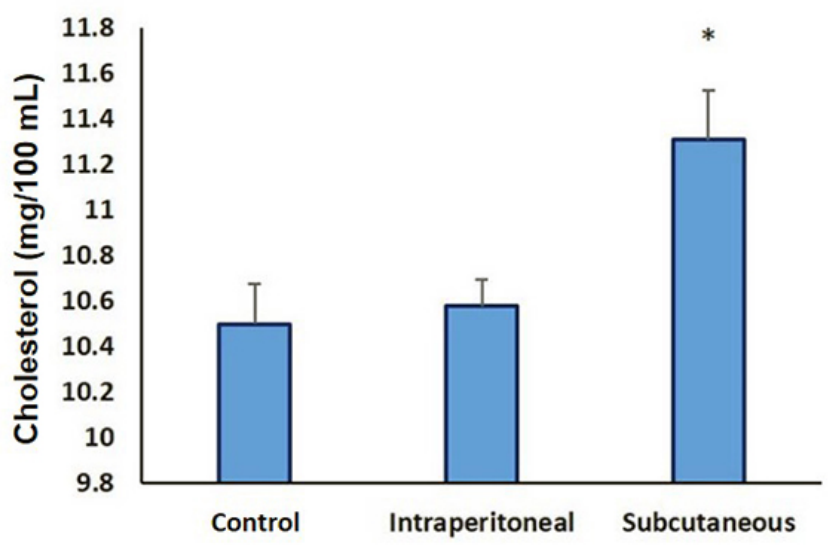

Figure 1. Levels of cholesterol and triglycerides in different rat groups, namely, control, intraperitoneal SAV-injected and subcutaneous SAV-injected rats.
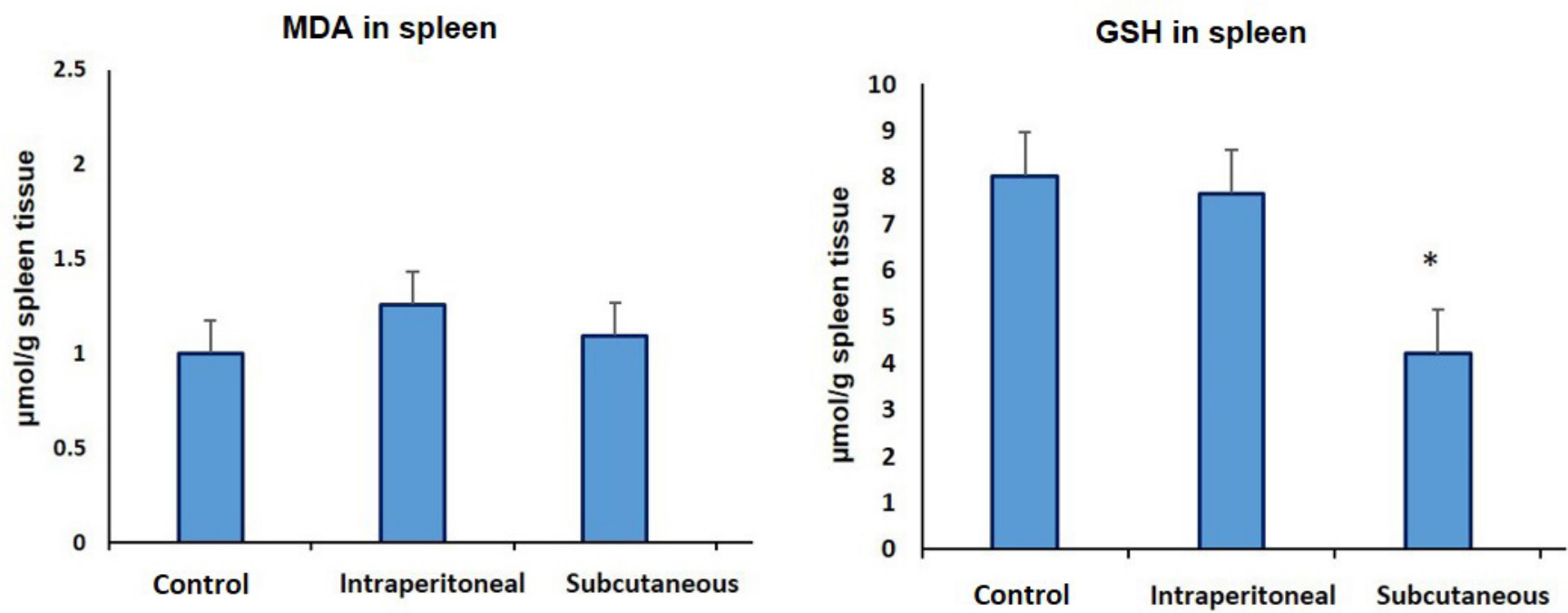

Figure 2. Levels of lipid peroxidation and glutathione in different rat groups, namely, control, intraperitoneal SAV-injected and subcutaneous SAV-injected rats. 

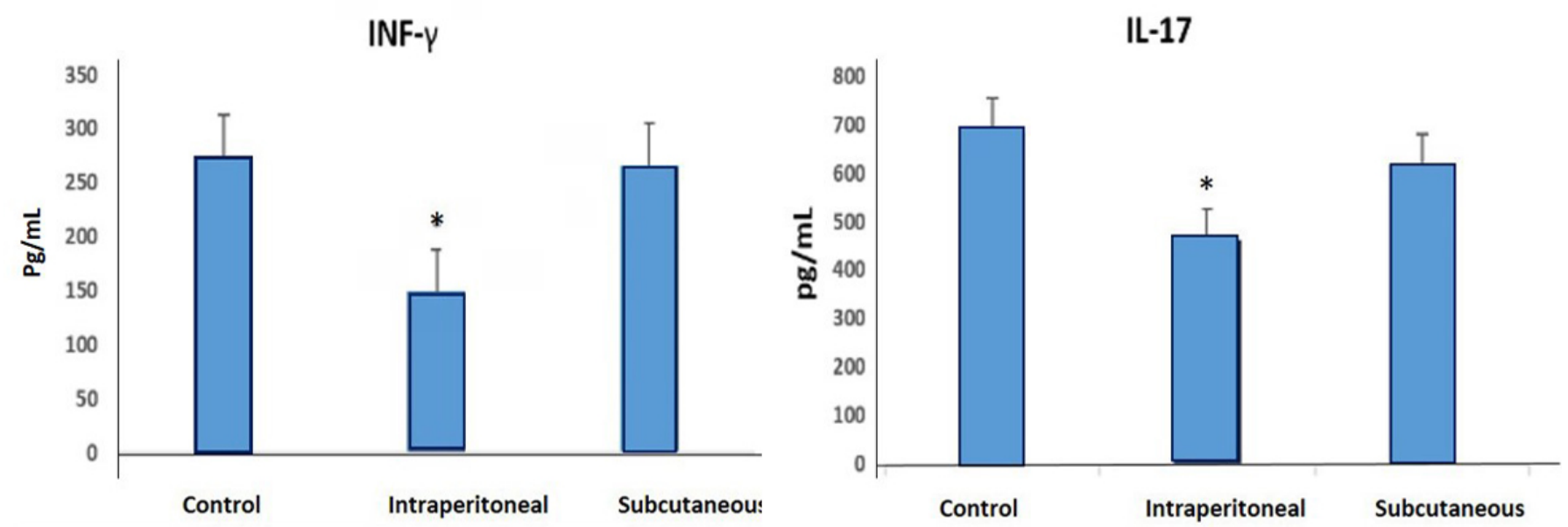

Figure 3. Levels of IFN- $\gamma$ and IL-17 in different rat groups, namely, control, intraperitoneal SAV-injected and subcutaneous SAV-injected rats.

\section{Liver}

Examination of the liver tissue showed that SAV was able to induce alterations. IP-SAV injected rats revealed mild changes. Infiltration of the hepatic tissue with inflammatory cells was observed in IP SAV-treated rat group with dilatation in the central vein with enlargement of the kupffer cells (Figure 8). On the contrary, severe histopathological alterations were observed in SC SAV-treated animals. Cytoplasmic vacoulations were observed into hepatocytes. The central vein in the animals was dilated and most of their sinusoids were remarkably narrow in shape. Severe infiltration of different inflammatory cell types was observed in the examined sections from SC SAV-treated animals. Hence, histopathological examination revealed that SC SAV-treatment exerts the more toxic effect of SAV than IP treatment on tested animals (Figure 8).

\section{Discussion}

Most ants inject secretions containing a range of bioactive elements in their bites that elicit inflammatory effects characterized by an increase in vascular permeability and neutrophil migration $[24,25,26]$. Although these effects have been thoroughly studied, the mechanism involved is poorly characterized up to this moment. We documented earlier how the low dose $(100 \mu \mathrm{g} / \mathrm{kg}$ dose of SAV) against lipopolysaccharides (LPS) influences AKT1, Fas, TNF- $\alpha$ and IFN- $\gamma$ mRNA expression in rats [18]. Herein, we have induced some immunological modulations by triggering the immune response with a high dose of SAV $(600 \mu \mathrm{g} / \mathrm{kg}$ of body weight) in rat model.

In the present study, SC SAV treated rats exhibited a profound elevation in total cholesterol and triglyceride levels. Recently, many studies using animal models in high fat and cholesterol diet showed a remarkable increase in circulating levels of lipocalin 2 and its hepatic expression. These modifications were associated with increased infiltration of neutrophils [27]. Therefore, neutrophils seem to get activated and then migrate towards high- fat concentration sites in vivo. The coronary heart disease-bearing patients express PMNs, which have lower phagocytosis and ROS-mediated destruction of the tissue/pathogens. Increasing age and high levels of cholesterol were found to be positively correlated in humans [28]. It is also important to mention that an improved lipid profile promotes efficient angiogenic stimulus and re-epithelialization during the wound healing process [29].

Numerous studies in the literature suggest that serum lipids, including cholesterol and TAGs, play a significant role in executing an appropriate immune response while encountering an infection or in autoimmune diseases [30, 31]. It is also reported that unsaturated fats (EPA, DHA, and oleic acids) modulate the immune response [32]. Such unsaturated fats may decrease or increase the level of various cytokines depending on the concurrent internal and external environment of the biological system [33, 34, 35]. Lipids provide energy and signal modulations for cellular expansion and membrane remodeling which are essential for both innate and adaptive immune responses [36, 37]. In the present study, the level of cholesterol and TAGs increases moderately in comparison with the control post SAV treatment. This might be attributable to the elevation of immune response in vivo, including the expansion of immune and allied cells, modulation of their membrane fluidity and production of cytokines.

Hence, it is also noteworthy that lipids regulate not only macrophage and T lymphocyte function but also their overall phenotype. The pathways that enhance lipid synthesis and accumulation lead to trigger a proinflammatory phenotype (Figure 2) while the other channels facilitating $\beta$-oxidation and lipid efflux dictate the immune cells towards an antiinflammatory phenotype. However, both phenotypes are the result of an intricate network of various pathways, and the final cellular fate occurs in a context of tissue type and disease state [36].

We also observed that subcutaneously injected SAV caused a profound increase in expression of MHC-II together with 

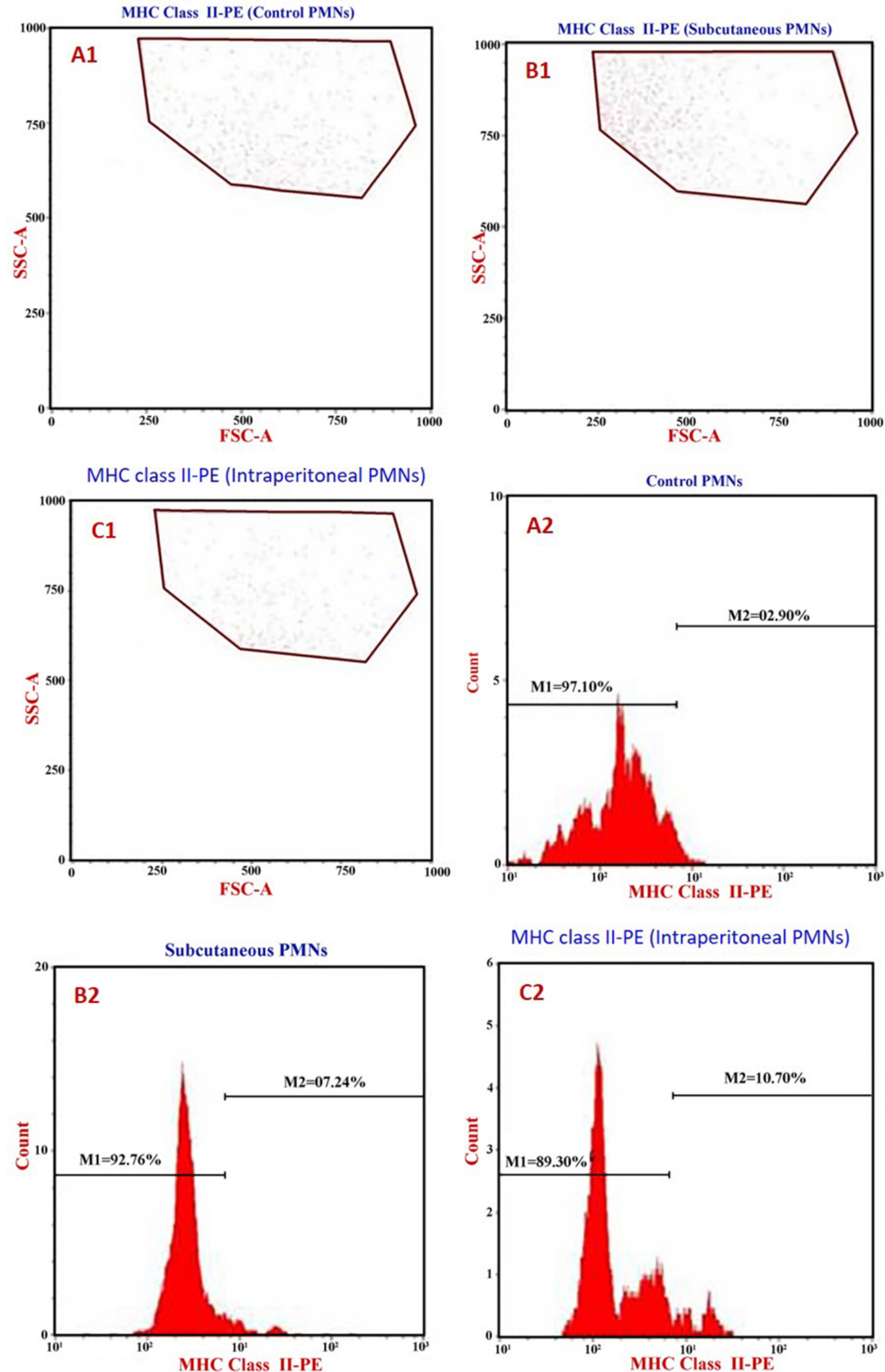

MHC class II-PE (Intraperitoneal PMNs)

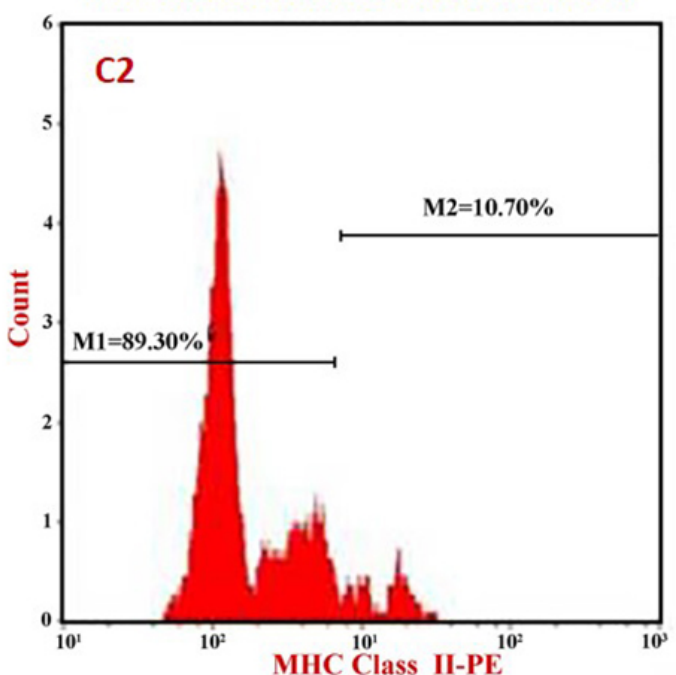

Figure 4. Representative cytoflourometry graphs of the MHC class II induction in the whole blood PMNs. (A1, A2) Unstimulated PMNs (control). (B1, B2) Subcutaneous SAV-stimulated PMNs. (C1, C2) Intraperitoneal SAV-stimulated PMNs. 

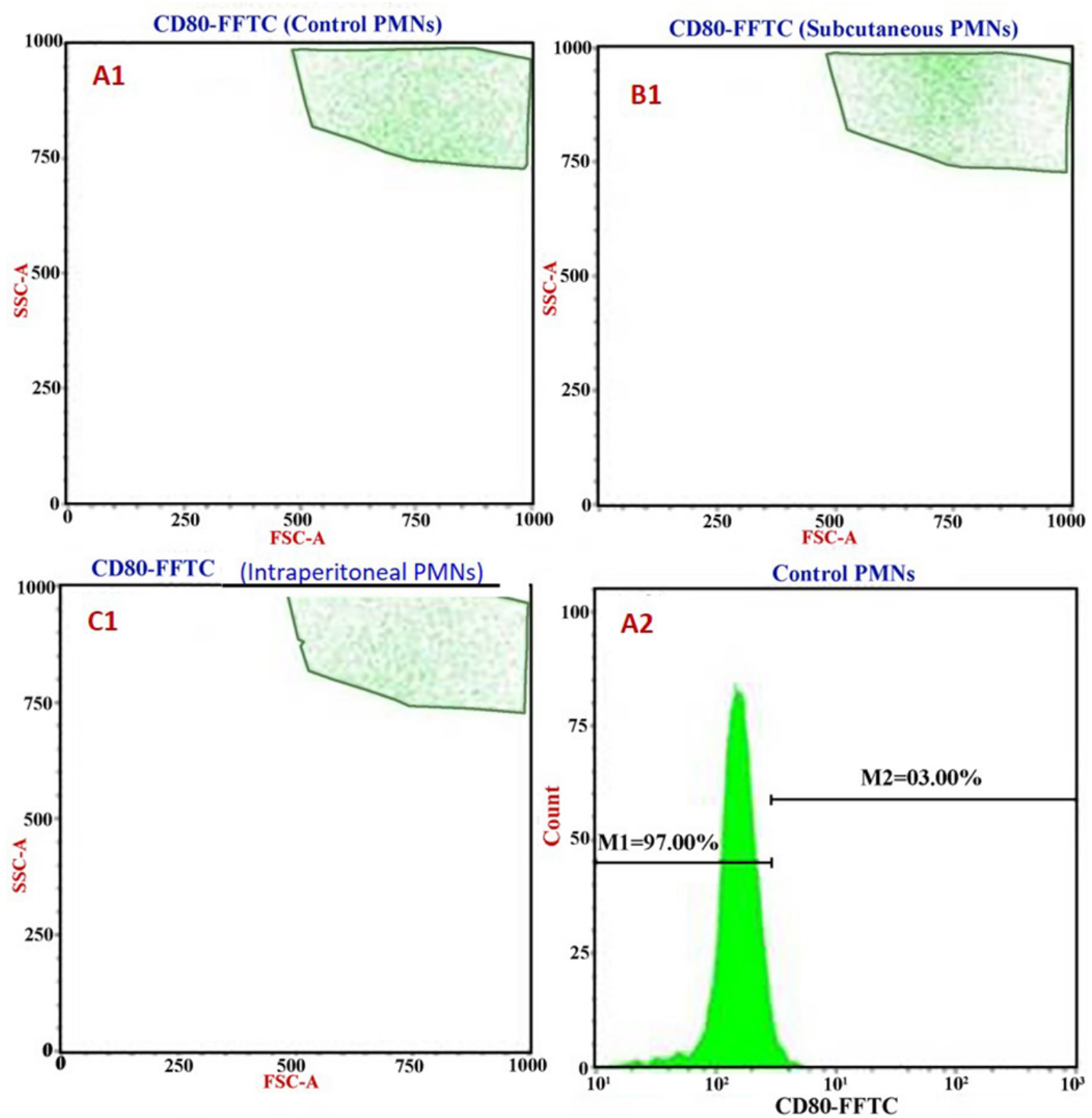

Subcutaneous PMNs

Intraperitoneal PMNs
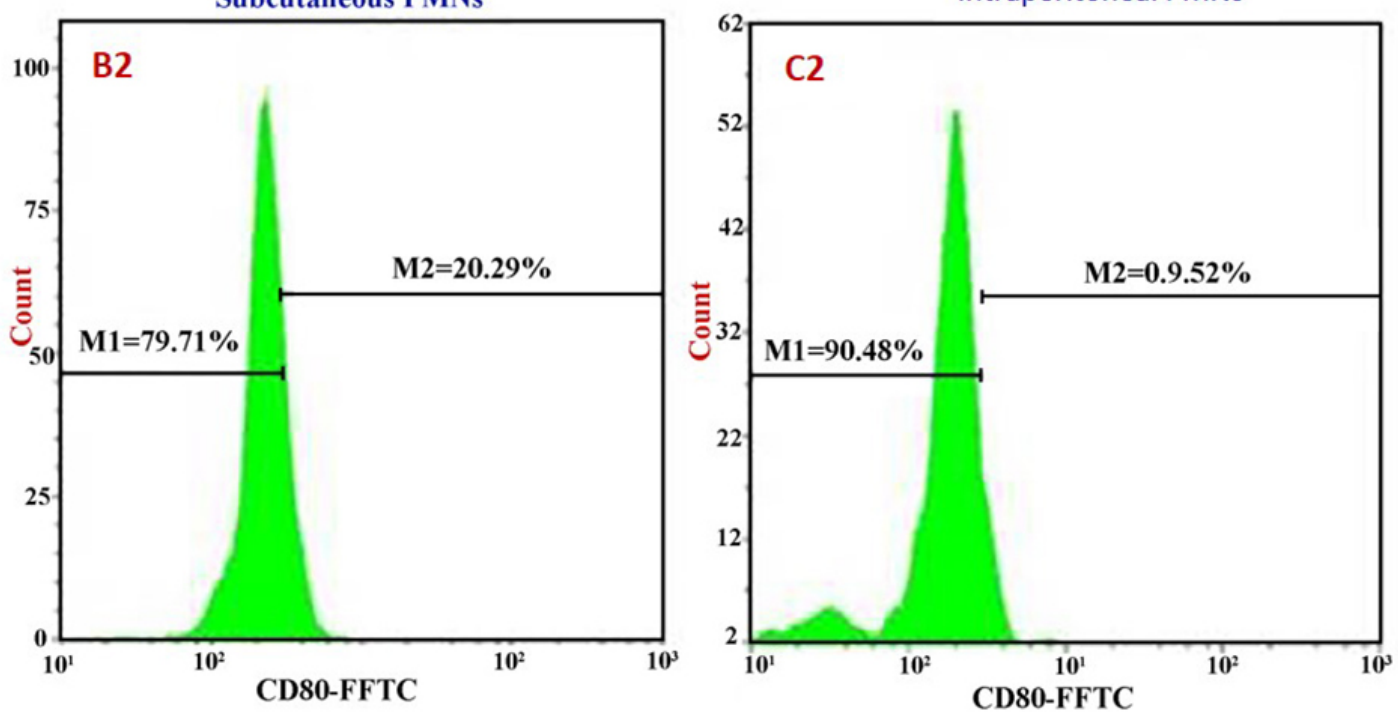

Figure 5. Representative cytoflourometry graphs of the CD80 induction in the whole blood PMNs. (A1, A2) Unstimulated PMNs (control). (B1, B2) Subcutaneous SAV-stimulated PMNs. (C1, C2) Intraperitoneal SAV-stimulated PMNs. 

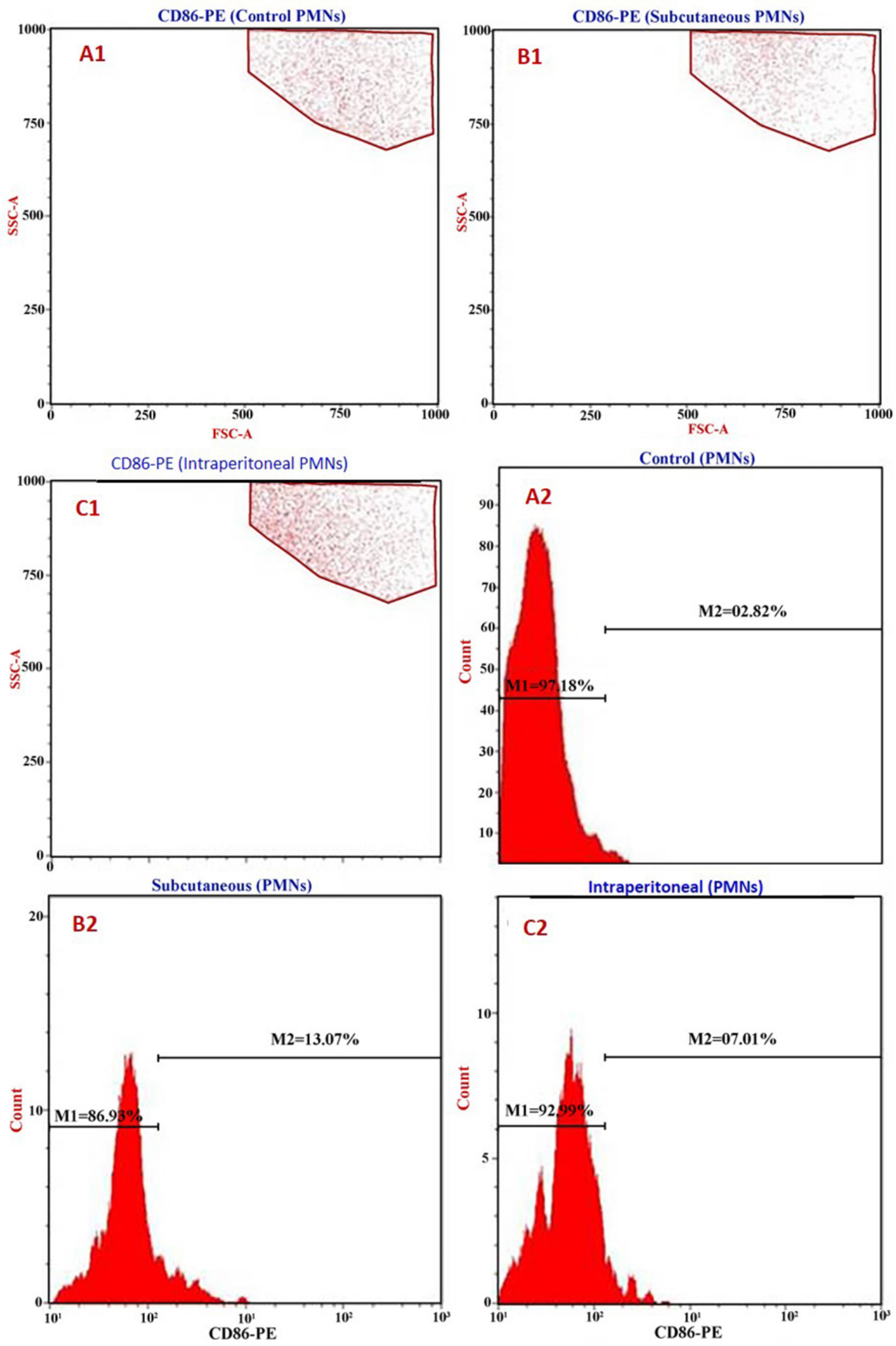

Figure 6. Representative cytoflourometry graphs of the CD86 induction in the whole blood PMNs. (A1, A2) Unstimulated PMNs (control). (B1, B2) Subcutaneous SAV-stimulated PMNs. (C1, C2) Intraperitoneal SAV-stimulated PMNs. 

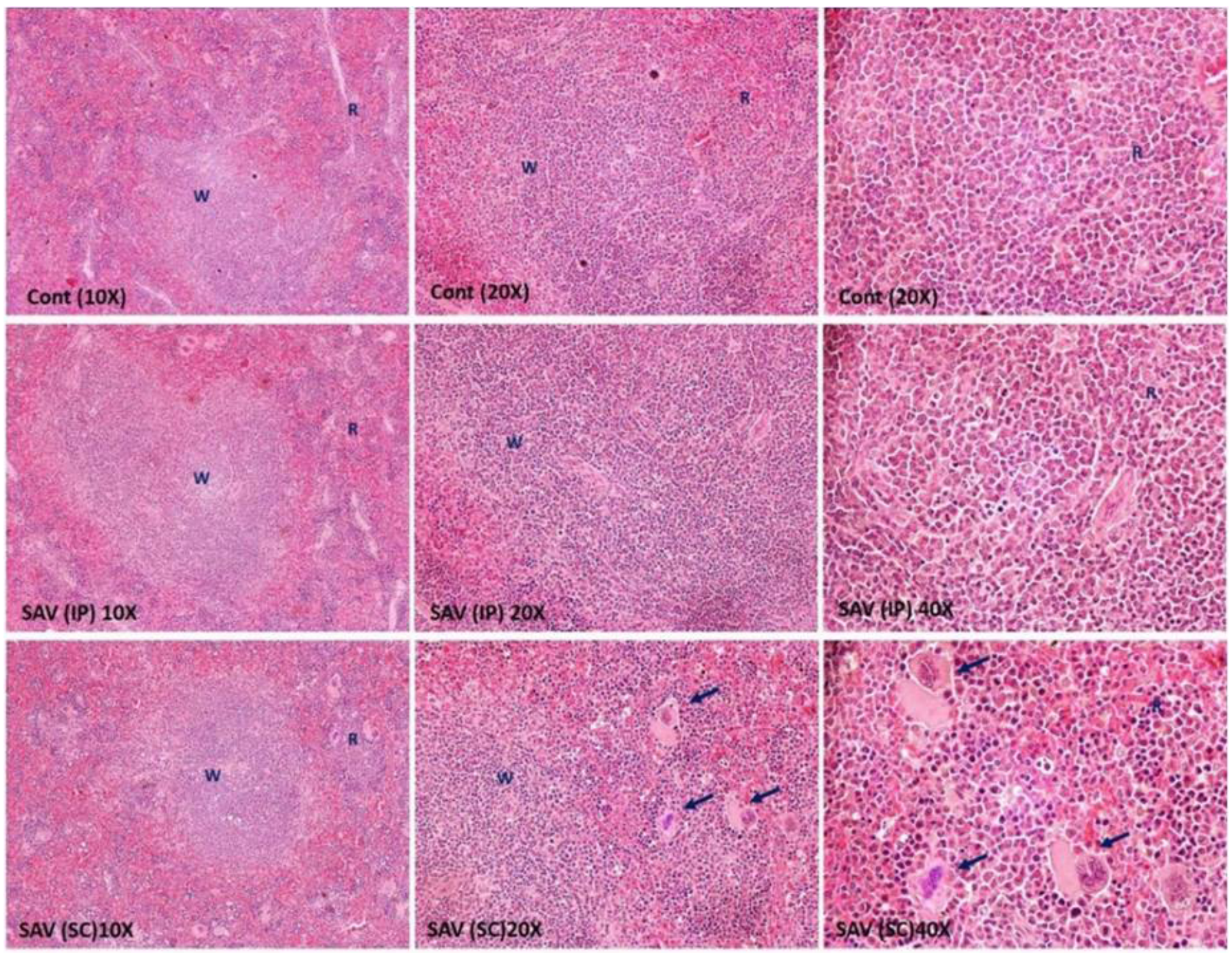

Figure 7. Representative photomicrographs of spleen tissue showing white (W) and red (R) pulps. Arrows show the megakaryocyte infiltration. Each group has three magnifications $(10 \times, 20 \times, 40 \times$ and HE). Many rat spleens were histologically examined for pathological changes. Cont: control group, SAV: samsum ant venom, IP: intraperitoneal, SC: subcutaneous.

the co-stimulatory molecules CD80 and CD86 (for migration) concomitant with a high concentration of both triglycerides and cholesterol in rats. Moreover, histological analysis showing hepatic infiltration with inflammatory cells in the same treated rats confirms the hypothesis.

The splenic homogenate exhibited no significant change in the level of MDA and GSH in rats injected with SAV through IP route. However, IP injection of SAV led to a significant decline in the concentrations of both cytokines - IFN- $\gamma$ and IL-17 - in comparison with the control group. Studies based on murine models suggest that infection raises the levels of IFN- $\gamma$ and PMN in lung and spleen tissue [37]. Besides, another immune parameter, NF-kB, is stimulated by oxidative stress, which is a central regulator of inflammatory and immune responses. Hence, its regulation ceases the level of crucial pro-inflammatory cytokines, such as IL-1 $\beta$, TNF- $\alpha$, IFN- $\gamma$ and IL- 6 [38].
IFN- $\gamma$ is the principal cytokine produced during TH1-type immune responses that are also released in response to IL-12. These results entail that SAV suppressed T-cell immune response. Many researchers have shown that isolated PMNs released IFN- $\gamma$ after IL-12 and TNF- $\alpha$ stimulation in vitro while other investigators failed to detect IFN- $\gamma$ after LPS stimulation [39]. Herein, it was found that isolated PMNs did not release IFN- $\gamma$ after SAV stimulation in vitro. The pro-inflammatory cytokine, IFN- $\gamma$, promotes Th1 responses, which down-regulate the Th2like immune responses that are hallmarks of allergic diseases. Hence, the allergy associated with the SAV on humans may be due to the decrease in the circulatory IFN- $\gamma$ in the present study.

Although activated $\mathrm{CD} 4^{+} \mathrm{T}$-cells are believed to be a major source of IL-17, activated CD8+ T-cells, PMNs and eosinophils also produce IL-17 [40,41]. IL-17 is a pro-inflammatory cytokine that acts synergistically with TNFa and IL-1 [42]. It was found 

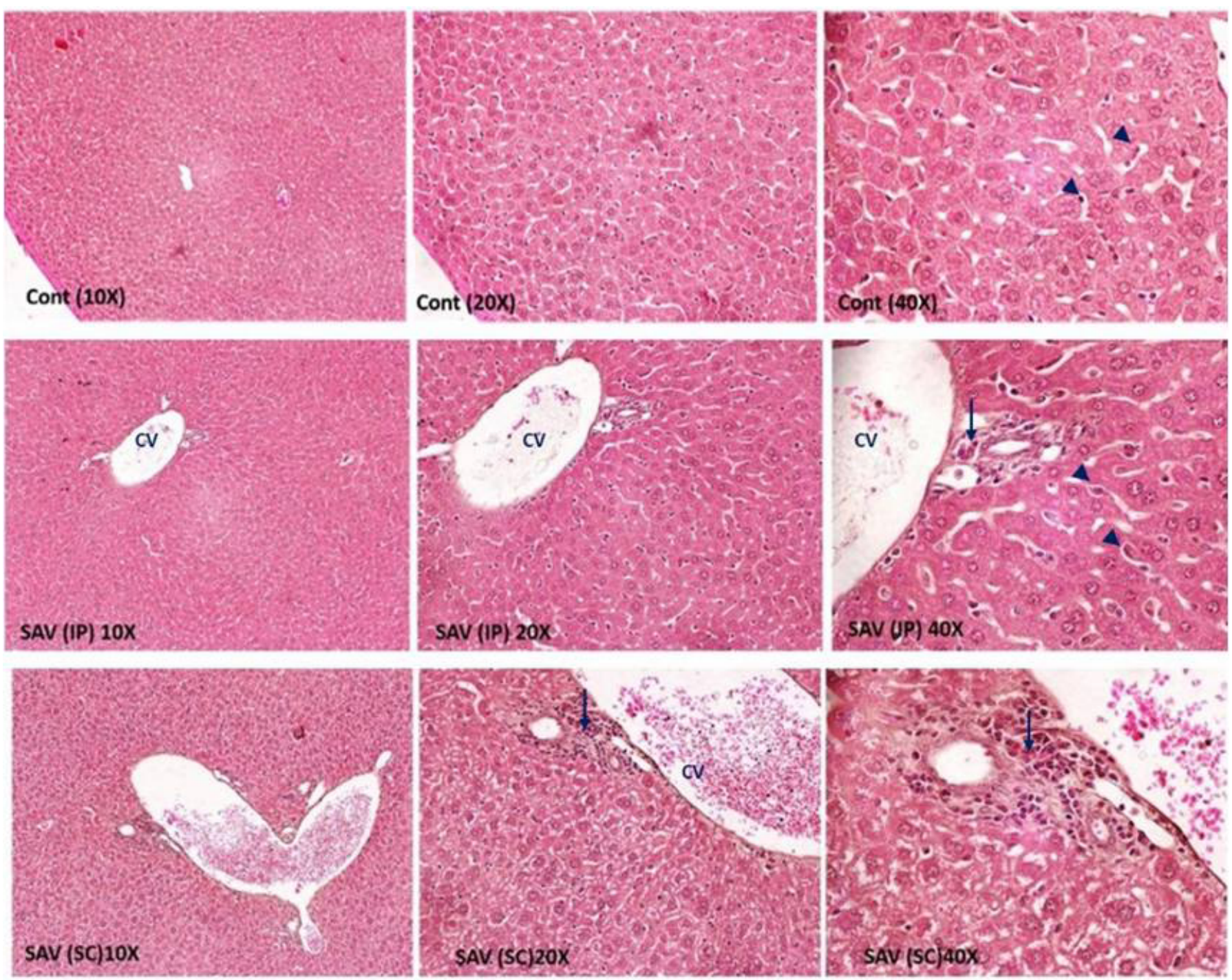

Figure 8. Representative photomicrographs of liver tissue. Each group has three magnifications $(10 \times, 20 \times, 40 \times$ and $\mathrm{HE})$. Arrows indicate inflammatory cells whereas arrow heads show Kuppffer's cells. CV: central vein, Cont: control group, SAV: samsum ant venom, IP: intraperitoneal, SC: subcutaneous.

that IL-17 production by cultured splenocytes was not affected in mice receiving anti-CD80 $\mathrm{mAb}$ [43]. Similarly, here, the IP injection of SAV was found to decline the level of IL-17 in blood samples with a significant upregulation of CD80 and CD86. However, it has been revealed that the enhancement of PMN infiltration and macrophage function was associated with markedly increased IL-17 in serum [4].

In another study, the blockade of CD80 and CD86 reduced IL-17 production. Although the severity of some diseases such as joint inflammation can be affected by various cytokines including Th17-associated IL-17, our results suggest that another pathway - by which CD80 and CD86 may contribute to the disease pathogenesis and tissue damge - is not upregulated by IL-17. Here, CD80 and CD86 may contribute to hepatic and splenic tissue damge through enhancing various inflammatory cytokines such as TNFa and IL-1. In particular, SC route of SAV injection was more efficient than IP by disturbing oxidative stability (GSH decrease) and increasing lipogram concentration.
This in turn may stimulate secretion of inflammatory cytokines that induce tissue damage (Figure 9).

The histological analysis confirms the biochemical and immunological results, showing the depletion of lymphocytes in the white pulp in IP SAV treated rats. It suggests a reduction in the lymphocyte number in peripheral blood and lymphoid organs that might be attributable to the significant reduction of IFN- $\gamma$ in plasma, which stimulates IL- 2 and IL-7 secretion. The dramatically declined lymphocyte number may indicate that lymphocytes are stressed by SAV toxicity starting with high levels of free radicals, increasing the levels of pro-inflammatory cytokines and ending by programmed cell death. Thus, results demonstrated that SAV may be capable of inducing splenocytic apoptosis.

The cytoplasmic vacuolation in hepatocytes is mainly a consequence of disturbance in lipid inclusions and metabolism during pathological changes. The vacuolar degeneration has been regarded by Ebaid et al. [44] to be an alteration produced 


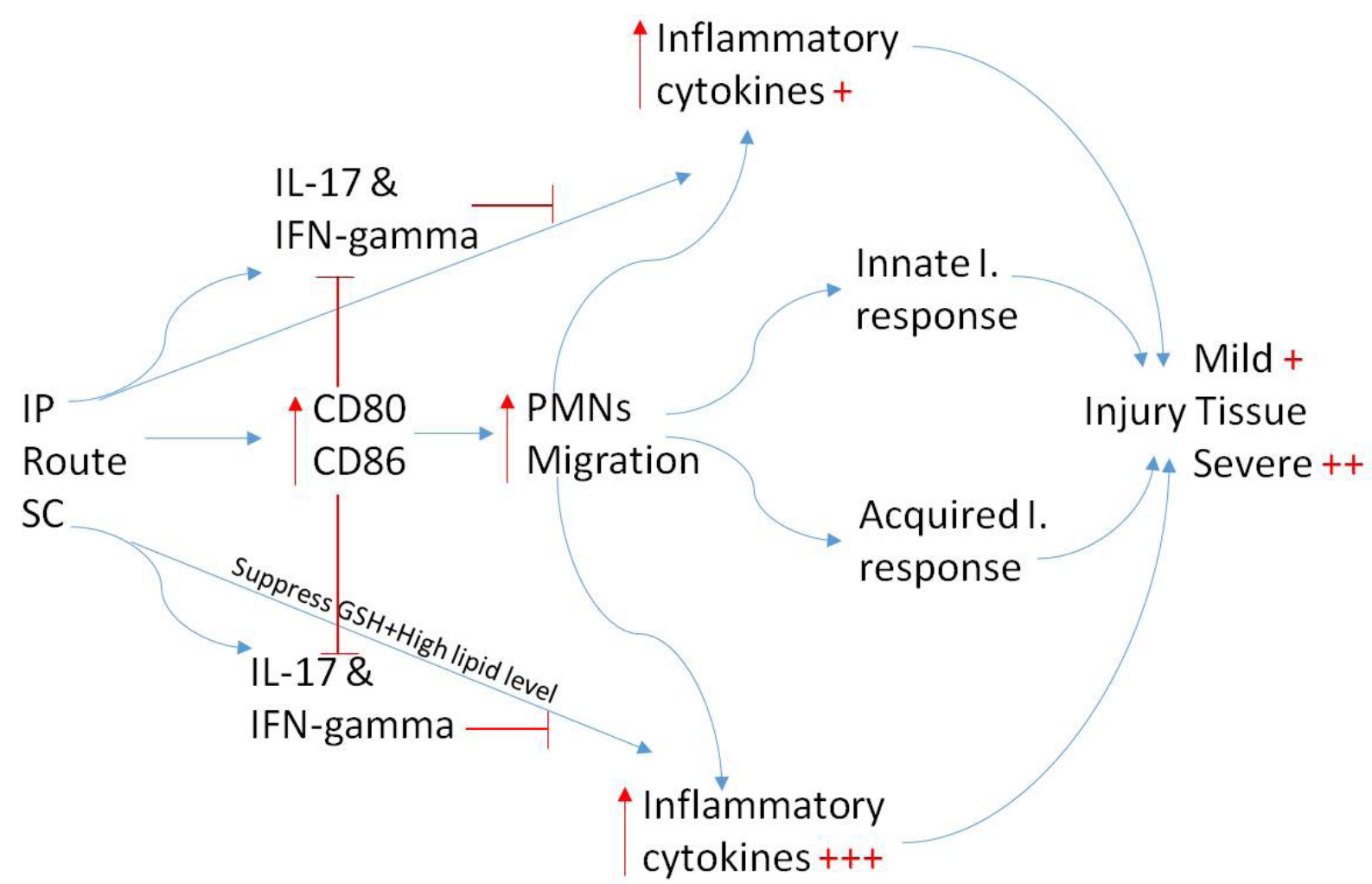

Figure 9. A summary of the effect of the two injection routes, intraperitoneal (IP) and subcutaneous (SC). Both IP and SC injections upregulate the expression of CD80 and CD86 on the PMNs (red arrows), and this directly support migration. Inflammatory cells increase cytokine secretion. By supressing GSH and elevating lipogram, SC was found to enhance tissue damge, $(++)$ and this may be due to increase inflammatory cytokines (+++). Results showed that upregulation of the expression of CD80 and CD86 did not affect IL-17 and IFN- $\gamma$ in SC rats (blocked line) and it was associated with a remarkably decrease of these two cytokins in IP rats.

to collect the injurious substances in the hepatocytes. The lymphocyte infiltration in the hepatic tissue is suggested to be a prominent response of body tissues facing injurious impacts.

Recently, a study demonstrated an association of PMNs with a specific IL-17/IL-22 environment in HIV-infected patients with highly activated PMNs [45]. This might be the reason for upregulation of MHC-II and the costimulatory molecules CD80 and CD86 on the PMNs after injection of SAV intraperitoneally and subcutaneously in rats. The activation and recruitment of PMNs can be stimulated by IL-15, IFN- $\gamma$, CSF-CSF, and IL- 8 $[46,47]$. Therefore, it is evident that the subcutaneous injection of SAV activates stronger stimulated PMNs than the intraperitoneal injection, which can be due to physiological and immunological alterations. This explains the significant lower expression of CD80 and CD86 on PMNs of the IP injection (9.5\%, and 7.01\%) in comparison with PMNs of the SC SAV injection (20.3\%, and $13.07 \%)$ in the present work.

\section{Conclusion}

The present study indicates that stimulation of PMNs by SAV leads to upregulation of MHC-II, CD 80, and CD 86. These molecules play a critical role in antigen presentation and, consequently, in proliferation of T-cells [48]. Hence, SAV is very effective in orchestrating the appropriate immune response by triggering acquired immune response indirectly. Moreover, the efficacy of SAV is more pronounced by subcutaneous administration in regard to intraperitoneal one. This aspect of SAV can be useful in the treatment of wide array of infections, autoimmune diseases and cancer.

\section{Abbreviations}

CD80 and CD86: costimulatory molecules; FACS: fluorescenceactivated cell sorter; GSH: reduced glutathione; HLA-II: human leukocyte antigen class II; IFN- $\gamma$ : interferon gamma; IL-17: interleukin-17; IP: intraperitoneal; LPS: lipopolysaccharides; MDA: lipid peroxidation; MHC-II: major histocompatability class II; PBS: phosphate buffered saline; PMNs: polymorphonuclear neutrophils; SAV: samsum ant venom; SC: subcutaneous; TAGs: triglycerides; TNF: tumour necrosis factor.

\section{Acknowledgments}

The authors would like to thank the Deanship of Scientific Research at King Saud University for funding this work through research roject no. RG-1440-120. 


\section{Availability of data and materials}

All data generated or analyzed during this study are included in this article.

\section{Funding}

The present study was funded by the Deanship of Scientific Research at King Saud University (research project no. RG1440-120).

\section{Competing interests}

The authors declare that they have no competing interests.F

\section{Authors' contributions}

HE, IH and IA conceived the research and study design. JA, AR and IH carried out animal handling. HE, BAS, JA, IH, AsM, AhM, AR and RS conducted experiments as per their expertise. HE, IH and IA analyzed the data. HE and IH drafted the manuscript. All authors read and approved the final manuscript

\section{Ethics approval}

All experiments conducted with animals were approved by the Departmental Animal Ethical Committee (College of Science, King Saud University, Riyadh) under protocol number 3/2/110623.

\section{Consent for publication}

Not applicable.

\section{References}

1. Fortin C, Larbi A, Dupuis G, Lesur O, Fulop T Jr. GM-CSF activates the JAK/STAT pathway to rescue polymorphonuclear neutrophils from spontaneous apoptosis in young but not elderly individuals. Biogerontology. 2007 Apr;8(2):173-87.

2. Rosa MFA, Vulcano M, Minnucci FS, Di Gianni PD, Isturiz MA. Inhibition of FcyR-dependent functions by $\mathrm{N}$-formyl-methionyl-leucyl-phenylalanine in human neutrophils. Clin Immunol Immunopathol. 1997 May;83(2):147-55.

3. Iking-Konert C, Wagner C, Denefleh B, Hug F, Schneider M, Andrassy K, et al. Up-regulation of the dendritic cell marker CD83 on polymorphonuclear neutrophils (PMN): divergent expression in acute bacterial infections and chronic inflammatory disease. Clin Exp Immunol. 2002 Dec;130(3):501-8.

4. Bian Z, Guo Y, Ha B, Zen K, Liu Y. Regulation of the inflammatory response: enhancing neutrophil infiltration under chronic inflammatory conditions. J Immunol. 2012 Jan 15;188(2):844-53.

5. Saqib U, Sarkar S, Suk K, Mohammad O, Baig MS, Savai R. Phytochemicals as modulators of M1-M2 macrophages in inflammation. Oncotarget. 2018 Apr 3;9(25):17937-50.

6. Krzyszczyk P, Schloss R, Palmer A, Berthiaum F. The Role of macrophages in acute and chronic wound healing and interventions to promote prowound healing phenotypes. Front Physiol. 2018 May 1;9:419.

7. Kabelitz T, Kappel C, Henneberger K, Benke E, Nöh C, Bäurle I. eQTL mapping of transposon silencing reveals a position-dependent stable escape from epigenetic silencing and transposition of AtMu1 in the Arabidopsis lineage. Plant Cell. 2014 Aug;26(8):3261-71.

8. Kroker M, Sydlik U, Autengruber A, Cavelius C, Weighardt H, Kraegeloh $A$, et al. Preventing carbon nanoparticle-induced lung inflammation reduces antigen-specific sensitization and subsequent allergic reactions in a mouse model. Part Fibre Toxicol. 2015 Jul 4;12:20.
9. Steen CJ, Janniger CK, Schutzer SE, Schwartz RA. Insect sting reactions to bees, wasps, and ants. Int J Dermatol. 2005 Feb; 44(2):91-4.

10. Al-Shahwan M, Al-Khenaizan S, Al-Khalifa M. Black (samsum) ant induced anaphylaxis in Saudi Arabia. Saudi Med. 2006 Nov;27(11):1761-3.

11. AlAnazi M, Al-Ashahrani M, Al-Salamah M. Black ant stings caused by Pachycondyla sennaarensis: a significant health hazard. Ann Saudi Med. 2009 May-Jun;29(3):207-11.

12. Ebaid H, Al-Tamimi J, Hassan I, Alhazza I, Al-Khalifa M. Antioxidant bioactivity of Samsum ant (Pachycondyla sennaarensis) venom protects against CCL4-induced nephrotoxicity in mice. Oxid Med Cell Longev. 2014;2014:763061.

13. Iking-Konert C, Vogt S, Radsak M, Wagner C, Hnsch G, Andrassy K. Polymorphonuclear neutrophils in Wegener's granulomatosis acquire characteristics of antigen presenting cells. Kidney Int. 2001 Dec;60(6):224762.

14. Abdel-Salam BKA, Ebaid H. Expression of CD11b and CD18 on polymorphonuclear neutrophils stimulated with interleukin-2. Cent Eur J Immunol. 2014;39(2):209-15.

15. Culshaw S, Millington OR, Brewer JM, Mclnnes IB. Murine neutrophils present Class II restricted antigen. Immunol Lett. 2008 Jun 15;118(1):49-54.

16. Hansch GM, Radsak M, Wagner C, Reis B, Koch A, Breitbart A, et al. Expression of major histocompatibility class II antigens on polymorphonuclear neutrophils in patients with Wegener's granulomatosis. Kidney Int. 1999 May;55(5):1811-8.

17. Nikbakhtzadeh MR, Tirgari S, Fakoorziba MR, Alipour H. Two volatiles from the venom gland of the Samsum ant, Pachycondyla sennaarensis. Toxicon. 2009 Jul;54(1):80-2.

18. Ebaid H, Al-Khalifa M, Isa AM, Gadoa S. Bioactivity of Samsum ant (Pachycondyla sennaarensis) venom against lipopolysaccharides through antioxidant and upregulation of Akt1 signaling in rats. Lipids Health Dis. 2012 Jul 23;11:93.

19. Christudoss P, Chacko G, Selvakumar R, Fleming JJ, Pugazhendhi S, Mathew $\mathrm{G}$. Expression of metallothionein in dimethylhydrazine-induced colonic precancerous and cancerous model in rat. J Cancer Res Ther. 2016 Oct-Dec;12(4):1307-12.

20. Bliss $\mathrm{Cl}$. The calculation of the dosage-mortality curve. Ann Appl Biol. 1935;22(1):134-67.

21. Gul Satar NY, Cangul IT, Topal A, Kurt H, Ipek V, Onel GI. The effects of Tarantula cubensis venom on open wound healing in rats. J Wound Care. 2017 Feb 2;26(2):66-71.

22. Aebi H. Catalase in vitro. Methods Enzymol. 1984;105:121-6.

23. Jollow DJ, Mitchell JR, Zampaglione NA, Gillette JR. Bromobenzeneinduced liver necrosis. Protective role of glutathione and evidence for 3,4-bromobenzene oxide as the hepatotoxic metabolite. Pharmacology. 1974;11(3):151-69.

24. Ohkawa $\mathrm{H}$, Ohishi N, Yagi K. Assay for lipid peroxides in animal tissues by thiobarbituric acid reaction. Anal Biochem. 1979 Jun;95(2):351-8.

25. Touchard A, Aili SR, Fox EGP, Escoubas P, Orivel J, Nicholson GM, et al. The biochemical toxin arsenal from ant venoms. Toxins. 2016 Jan;8(1):30.

26. Bouzid W, Klopp C, Verdenaud M, Ducancel F, V'etillard A. Profiling the venom gland transcriptome of Tetramorium bicarinatum (Hymenoptera: Formicidae): the first transcriptome analysis of an ant species. Toxicon. 2013 Aug;70:70-81.

27. Sousa PL, Quinet YP, Cavalcante Brizeno LA, Sampaio TL, Torres AF, Martins AM, et al. The acute inflammatory response induced in mice by the venom of the giant ant Dinoponera quadriceps involves macrophage and interleukin-1 $\beta$. Toxicon. 2016 Jul;117:22-9.

28. Ye D, Yang K, Zang S, Lin Z, Chau HT, Wang Y, Zhang J, et al. Lipocalin-2 mediates non-alcoholic steatohepatitis by promoting neutrophilmacrophage crosstalk via the induction of CXCR2. J Hepatol. 2016 Nov;65(5):988-97.

29. Ebaid H, Ahmed OM, Mahmoud AM, Ahmed RR. Limiting prolonged inflammation during proliferation and remodeling phases of wound healing in streptozotocin-induced diabetic rats supplemented with camel undenatured whey protein. BMC Immunol. 2013 Jul 25;14:31.

30. Brown MS, Goldstein J.. Receptor-mediated control of cholesterol metabolism. Study of human mutants has disclosed how cells regulate 
a substance that Is both vital and lethal. Science (Wash. D. C.). 1976;19(1):150-2.

31. Vitale JJ, Broitman SA. Lipids and immune function. Cancer Res. 1981 Sep;41(9 Pt 2):3706-10.

32. de Pablo MA, Ortega E, Gallego AM, Alvarez C, Pancorbo P, Alvarez de Cienfuegos $G$. The effect of dietary fatty acid manipulation on phagocytic activity and cytokine production by peritoneal cells from Balb/c mice. J Nutr Sci Vitaminol (Tokio). 1998 Feb;44(1):57-67.

33. Fritsche KL, Byrge M, Feng C.. Dietary g-3 polyunsaturated fatty acids from fish oil reduce interleukin-12 and interferon- gamma production in mice. Immunol. Lett. 1999 Feb;65(3):167-73.

34. Hardardottir I, Kinsella JE. Tumor necrosis factor production by murine resident peritoneal macrophages is enhanced by dietary $n-3$ polyunsaturated fatty acids. Biochim Biophys Acta. 1991 Nov 12;1095(3):187-95.

35. de Pablo MA, Angeles Puertollano M, Alvarez de Cienfuegos G. Immune cell functions, lipids and host natural resistance. FEMS Immunol Med Microbiol. 2000 Dec;29(4):323-8.

36. Hubler MJ, Kenned AJ. Role of lipids in the metabolism and activation of immune cells. J Nutr Biochem. 2016 Aug;34:1-7.

37. Chan SS, Monteiro HP, Deucher GP, Abud RL, Abuchalla D, Junqueira VB. Functional activity of blood polymorphonuclear leukocytes as an oxidative stress biomarker in human subjects. Free Radic Biol Med. 1998 Jun;24(9):1411-8.

38. Ellis TN, Beaman BL. Murine polymorphonuclear neutrophils produce interferon- $\gamma$ in response to pulmonary infection with Nocardia asteroides. J Leukoc Biol. 2002 Aug;72(2):373-81.

39. Siomek A. NF-kB signaling pathway and free radical impact. Acta Biochim Pol. 2012;59(3):323-31.

40. Yeaman GR, Collins JE, Currie JK, Guyre PM, Wira CR, Fanger MW. IFNgamma is produced by polymorphonuclear neutrophils in human uterine endometrium and by cultured peripheral blood polymorphonuclear neutrophils. J Immunol. 1998 May 15;160(10):5145-53.

41. Kindt T, Goldsby R, Osborne B, Kuby J. Editors. Kuby Immunology. 6th Edition. San Francisco; W.H. Freeman; 2007.

42. Wu Q, Martin RJ, Rino JG, Breed R, Torres RM, Chu HW. IL-23-dependent IL-17 production is essential in neutrophil recruitment and activity in mouse lung defense against respiratory Mycoplasma pneumoniae infection. Microbes Infect. 2007 Jan;9(1):78-86.

43. Odobasic D, Leech MT, Xue JR, Holdsworth SR. Distinct in vivo roles of CD80 and CD86 in the effector T-cell responses inducing antigen-induced arthritis. Immunology. 2008 Aug;124(4):503-13.

44. Ebaid H, Dkhil MA, Danfour MA, Tohamy A, Gabry MS. Piroxicaminduced hepatic and renal histopathological changes in mice. Libyan J Med. 2007;2(2):82-9.

45. Chiricozzi A, Guttman-Yassky E, Suárez-Fariñas M, Nograles KE, Tian $\mathrm{S}$, Cardinale I, et al. Integrative responses to IL-17 and TNF-a in human keratinocytes account for key inflammatory pathogenic circuits in psoriasis. J Invest Dermatol. 2011 Mar;131(3):677-87.

46. Campillo-Gimenez L, Casulli S, Dudoit Y, Seang S, Carcelain G, LambertNiclot S, et al. Neutrophils in anti-retroviral therapy-controlled HIV demonstrate hyper-activation associated with a specific IL-17/IL-22 environment. J Allergy Clin Immunol. 2014 Nov;134(5):1142-52.

47. Abdel-Salam BK, Ebaid H. Upregulation of major histocompatibility complex class II, CD83, CD64, and CD14 on polymorphonuclear neutrophils stimulated with interleukin-15. J Microbiol Immunol Infect. 2008 Dec;419(6):462-8.

48. Ethuin F, Gérard B, Benna JE, Boutten A, Gougereot-Pocidalo MA, Jacob $\mathrm{L}$, et al. Human neutrophils produce IFN- $\gamma$ upon stimulation by IL-12. Lab Invest. 2004 Oct;84(10):1363-71. 